\title{
Squamous Cell Carcinoma of the Tongue in a Patient on Ustekinumab as the Treatment of Psoriasis
}

\author{
Chii-Shyan Wang ${ }^{1}$ Hsuan-Hsiang Chen ${ }^{2 *}$ \\ ${ }^{1}$ Department of Dermatology, En Chu Kong Hospital, New Taipei City, Taiwan \\ 2 Department of Dermatology, National Taiwan University Hospital and National Taiwan University College of Medicine, Taipei, Taiwan
}

Received: May 31, 2017; Accepted: July 15, 2017; Published: August 10, 2017

*Corresponding author: Hsuan-Hsiang Chen, Department of Dermatology, National Taiwan University Hospital and National Taiwan University College of Medicine, 7, Chung-Shan South Road, Taipei, Taiwan, Tel : +886-2-2356-2141; Fax: +886-2-2393-4177, E-mail : beauty101@gmail.com

\begin{abstract}
Ustekinumab is a human monoclonal antibody selectively targeting the shared p40 subunit of interleukin-12 (IL-12) and IL-23. Its efficacy for the treatment of psoriasis has been well documented in previous trials. We report a rare case of a patient who developed Squamous Cell Carcinoma (SCC) of the tongue after the commencement of ustekinumab as the treatment of plaque type psoriasis. To our knowledge, no link between ustekinumab and tongue SCC has been demonstrated before. Our report suggests that ustekinumab may induce the development of oral SCC in predisposed individuals.

Keywords: Squamous cell carcinoma; Tongue; Ustekinumab; Psoriasis;
\end{abstract}

\section{Introduction}

Psoriasis is a chronic inflammatory dermatosis affecting $2-3 \%$ of the general population worldwide. It may significantly impair these patients' emotional, social and physical quality of life. In patients with extensive psoriasis, a satisfactory treatment response to traditional topical and systemic therapies may be difficult to achieve. The effectiveness of new biological agents to treat recalcitrant psoriasis provides clinicians with more options in improving their patients' quality of life. However, there is still some debate regarding the risk of developing malignancy and progression of malignancy in patients with psoriasis treated with biologics. Herein, we report a rare case of a patient who developed SCC of the tongue after the commencement of ustekinumab as the treatment of plaque type psoriasis. The potential risks of malignancies from ustekinumab were discussed.

\section{Case Report}

A 65-year-old woman with a history of chronic plaque psoriasis (Figure 1) has received narrow-band ultraviolet-B therapy (NB-UVB), methotrexate, acitretin, cyclosporine, leflunomide, and ustekinumab (see Table 1) apart from topical therapy since 2011 .

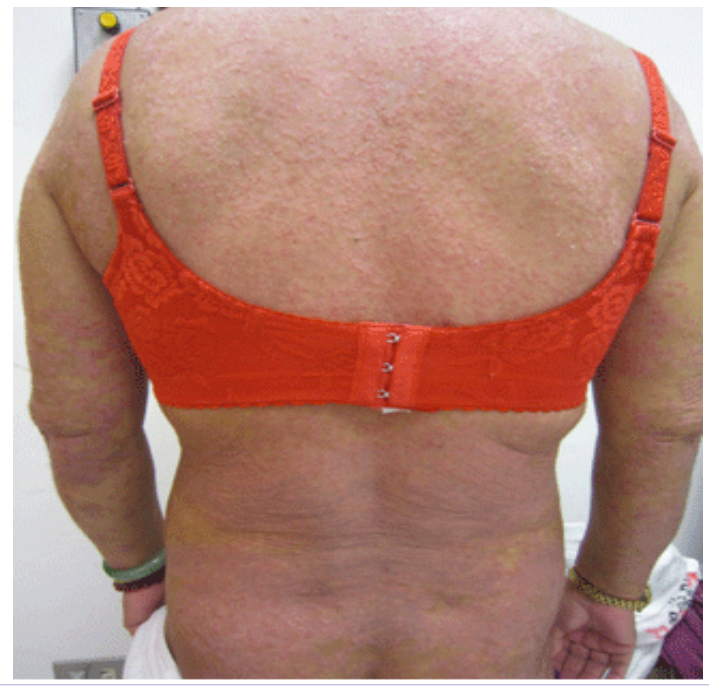

Figure 1: The extensive distribution of chronic plaque psoriasis in this patient

\begin{tabular}{|c|c|}
\hline \multicolumn{2}{|c|}{ Table 1: Patients' previous treatment of psoriasis } \\
\hline Previous treatment & Details \\
\hline Phototherapy & $\begin{array}{c}\text { Dose: } 200-720 \mathrm{~mJ} / \mathrm{cm} 2,2-3 \text { sessions/week } \\
\text { Duration: } 2014\end{array}$ \\
\hline Methotrexate & $\begin{array}{c}\text { Dose: } 5-15 \mathrm{mg} \text { daily, total } 290 \mathrm{mg} \\
\text { Duration: } 2011,2014\end{array}$ \\
\hline Acitretin & $\begin{array}{c}\text { Dose: } 25 \mathrm{mg} \text { daily, total 3,500mg } \\
\text { Duration: } 2013\end{array}$ \\
\hline Cyclosporine & $\begin{array}{c}\text { Dose: } 100-200 \mathrm{mg} \text { daily, total } 28,800 \mathrm{mg} \\
\text { Duration: } 2013-2014\end{array}$ \\
\hline & $\begin{array}{c}\text { Dose:45mg, 3 month interval, total } 405 \mathrm{mg} \\
\text { Duration:2014-2016 } \\
\text { Baseline PASI: } 16.1\end{array}$ \\
\hline Ustekinumab & \\
\hline
\end{tabular}


It is noteworthy that this patient developed one ulcerative nodular lesion on the right lateral aspect of her tongue (Figure 2) after the treatment of ustekinumab from 2016. No history of previous Human Papillomavirus (HPV) infection (including oral, genital and cutaneous infection) was identified. No tobacco smoking, betel nut chewing, or alcohol use were noted, either.

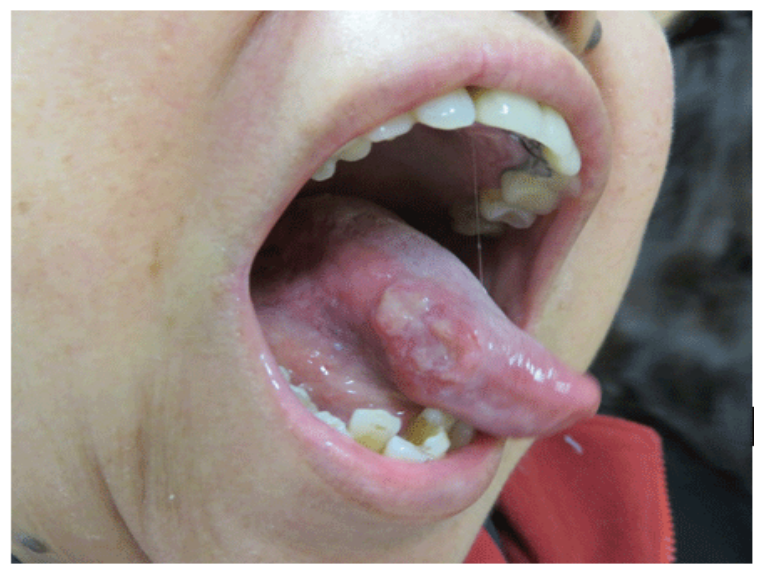

Figure 2: There was one ulcerative nodular lesion on the right lateral aspect of the tongue

The lesion was biopsied and histology revealed this lesion to be well to moderately differentiated SCC composed of sheets and nests of neoplastic cells with keratinization and intercellular bridges (Figure 3 and 4). The tumor cells invade subepithelial stroma. The RNA scope-based in situ Hybridization (ISH) of HPV high-risk and low-risk panels (RNAscope Reagent Kits, Advanced Cell Diagnostics, USA) showed no E6/E7 mRNA transcripts was detected.

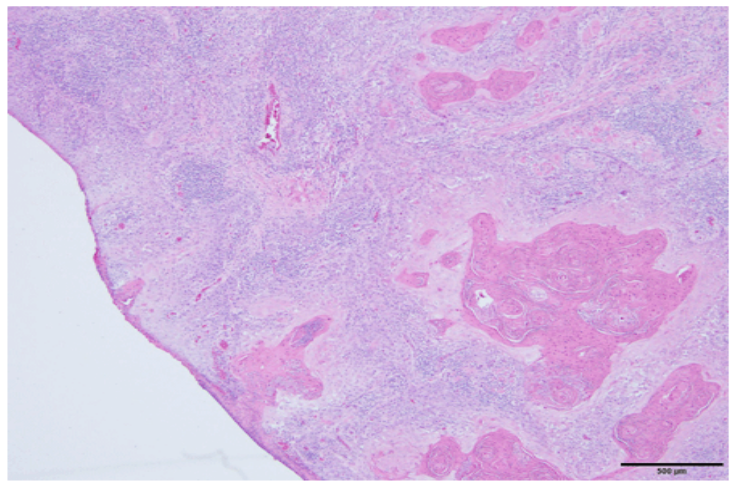

Figure 3: Well to moderately differentiated SCC composed of sheets and nests of neoplastic cells invading subepithelial stroma (H \& E, original magnification $\times 40$ )

\section{Discussion}

Patients with psoriasis are recognized to have a higher risk of cutaneous malignancy than the general population. Individuals with less severe psoriasis were slightly more likely to develop a malignancy compared to those with hypertension (Risk Ratio [RR] 1.13; 95\% confidence interval [CI], 1.03-1.25). Individuals

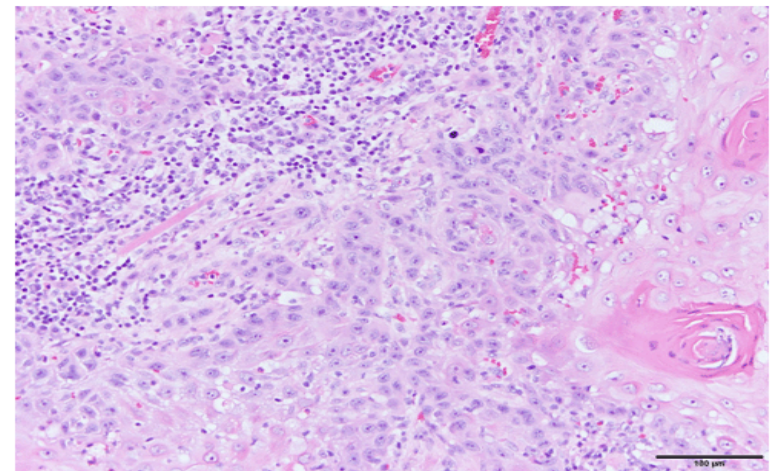

Figure 4: Neoplastic cells with keratinization and intercellular bridges (H\&E, original magnification $\mathrm{x} 200$ )

with severe psoriasis were even more likely to develop a malignancy compared to those with hypertension (RR 1.78; 95\% CI, 1.32-2.40). Most of these cancers were lymphoproliferative malignancies and non-melanoma skin cancer (NMSC). After excluding both of these cancer categories, the risk for malignancy was still slightly elevated for the severe psoriasis group (RR 1.46; 95\% CI, 1.04-2.05) [1]. The latest population-based cohort study of 198,366 patients with psoriasis revealed adjusted hazards ratios (aHRs) of cancer excluding NMSC were 1.06 (95\% CI, 1.021.09), 1.06 (95\% CI, 1.02-1.09), and 1.08 (95\% CI, 0.96-1.22) in the overall, mild, and severe psoriasis group. For NMSC, the aHRs were 1.12 (95\% CI, 1.07-1.16), 1.09 (95\% CI, 1.05-1.13), and 1.61 (95\% CI, 1.42-1.84) [2]. The association between psoriasis and cancer was primarily driven by NMSC, lymphoma, and lung cancer. This might be largely secondary to the effects of immunosuppressive agents and phototherapy used for the control of the disease [3]. As a conventional systemic treatment for psoriasis, cyclosporine has been shown to increase the risk of cutaneous and other malignancies. An increased risk of skin cancer also exists with psoralen and ultraviolet-A (PUVA) or NB-UVB [4]. However, other comorbidities such as tobacco smoking and alcohol use must be considered when measuring the cancer risk in psoriasis [5]. Our patient had received cyclosporine and NB-UVB phototherapy, but no other comorbidities such as tobacco smoking, betel nut chewing, or alcohol use were identified. Because the oral mucosa was not irradiated during NB-UVB phototherapy, the influence of phototherapy in our patient is neglectable. However, the effect of cyclosporine on the increased risk of cancer should be considered.

The disordered regulation of interleukin (IL)-12 and IL-23 has been associated with many immune-mediated diseases, including psoriasis [6]. The expression of both cytokines is increased in the plaques of psoriasis. Genetic polymorphisms in the gene encoding the shared p40 subunit common to these cytokines have also been demonstrated in patients with psoriasis [7]. These heterodimeric cytokines are involved in innate and adaptive immune responses and contribute to natural killer cell activation and CD4+ T-cell differentiation and activation. Ustekinumab, the first market-approved member of a new biological therapy family targeting IL-12 and IL-23, can interrupt the disordered regu- 
lation of these cytokines, and represents an effective therapeutic option for extensive psoriatic disease [8].

However, specific aspects of the anti-IL-12 and anti-IL-23-directed immunosuppression secondary to ustekinumab may directly affect innate defense mechanisms against tumorigenesis. The potential risk for development of malignancy is concerned. Recently, two cases of patients who developed multiple eruptive cutaneous SCC soon after the commencement of ustekinumab were reported. Other than ustekinumab, their patients had preexisting risk factors, particularly extended periods of therapy with PUVA, which may contribute a predisposition to the tumors' emergence. Young and Czarnecki concluded that ultraviolet radiation-induced subclinical tumors were present in their patients at the onset of therapy. The potential immunosuppressive effect of ustekinumab perhaps merely acted to unmask the multiple subclinical tumors [9]. Contrary to their cases, our patient did not receive PUVA previously. The possibility of PUVA related subclinical tumors before the onset of ustekinumab therapy is not likely in our case.

To understand the potential risks of malignancies from ustekinumab therapy, five randomized placebo-controlled trials of ustekinumab for the treatment of moderate-to-severe plaque psoriasis and three meta-analyses of randomized controlled trials and open-label extension studies were identified through literature review [10-18]. In general, malignancy excluding NMSC was not significantly increased in patients receiving long-term ustekinumab therapy when compared with The National Cancer Institute's Surveillance Epidemiology and End Results (NCI SEER) database $[15,17]$.

Among these studies, Gordon et al. found an overall malignancy rate of $0.3 \%$ in ustekinumab-treated patients, which is comparable with $0.4 \%$ in placebo-treated patients [15]. Rates of NMSC and rates of all other malignancies were also comparable among ustekinumab-treated and placebo-treated patients. The incidence of malignancies was approximately 1.30 per 100 patient-years (PY), which is not higher than that of 1.70 per 100 PY reported in placebo-treated patients. Rates of malignancy in the ustekinumab 45- and 90-mg groups were 1.33 and 1.24 per $100 \mathrm{PY}$, respectively, demonstrating no apparent dose response for malignancy risk. It is worth noting that 2 of 27 malignancies other than NMSC in ustekinumab-treated patients were head and neck cancers. However, the association between SCC of tongue and ustekinumab was not clear because no further details were provided in their report. Similarly, a 4-year data by Reich et al. revealed that the incidence of malignancy other than NMSC was not elevated, with a rate of 0.39 per $100 \mathrm{PY}$ in the ustekinumab groups, and 0.44 per $100 \mathrm{PY}$ in the placebo group [19]. Another 5 -year study by Papp et al. also showed that the rates of malignancies other than NMSC were comparable between the ustekinumab $45 \mathrm{mg}$ ( 0.59 per $100 \mathrm{PY}$ ) and $90 \mathrm{mg}$ ( 0.61 per $100 \mathrm{PY}$ ) groups without increasing trend. Overall, the incidence of malignancies other than NMSCs in ustekinumab-treated patients $(0.60$ per 100 PY) was consistent with that expected in the general U.S. population (range 0.54-0.72 per $100 \mathrm{PY}$ ) [17]. There is no evidence of a shift towards a pattern of malignancy indicative of severe immunosuppression. Two recent reports from observational data of Psoriasis Longitudinal Assessment and Registry (PSOLAR) also showed the incidence rate for malignancy excluding NMSC was 0.48 to 0.53 per $100 \mathrm{PY}$ in the ustekinumab groups [20,21]. None of the biologics was associated with increased risk of malignancy. Increasing age and previous history of malignancy were the only indicators of malignancy. Based on these previous reports mentioned above, it is hard to tell whether the occurrence of SCC in our patient was truly induced by the therapy of ustekinumab.

HPV infection has been considered a potential risk factor for the development of oral tongue SCC. Many investigators have reported HPV infection rates in SCC of the oral tongue ranging from $0 \%$ to $100 \%$ [22]. The large discrepancy in HPV infection rates among studies is possibly attributed not only to the different methods for HPV detection, but also to the different sample size, the sample type and storage conditions (i.e. formalin fixed or fresh biopsies) and geographic variation. A study by Tsimplaki et al showed that $11.3 \%$ of the oral tongue samples were positive for HPV DNA. High-risk HPV (hrHPV) infection was observed in $7.5 \%$ of SCC of the oral tongue [22]. Because the detection of HPV in oral cancer alone does not prove their possible implication in carcinogenesis, the expression of E6/E7 mRNA from hrHPV types in oral cavity cancer is a necessary step for the onset of HPV-infected head and neck carcinomas. Tsimplaki et al revealed that $9.4 \%$ of SCC of the oral tongue were positive for hrHPV E6/ E7mRNA expression, suggesting that HPV may be implicated in the pathogenesis of oral tongue cancer [22]. However, a statistically significant association was not observed between HPV and SCC in the oral cavity in the previous report by Saghravanian et al, even though they found $13.1 \%$ of SCC of oral cavity showed HPV positivity [23]. Our patient did not have previous HPV infection. The pathological exam and RNAscope-based ISH revealed no HPV infection, either. Therefore, it is unlikely that HPV can induce carcinogenesis in our patient.

\section{Conclusion}

In conclusion, we report a rare case of a patient who developed SCC of the tongue after the commencement of ustekinumab as the treatment of plaque type psoriasis. It is not clear whether the occurrence of SCC was truly induced by the therapy of ustekinumab. Although previous trials and studies showed no increased risk for the development of malignancy, the combination of cyclosporine and ustekinumab may be the trigger factors to develop SCC in our patient. We suggest that it is mandatory for clinicians to perform a thorough malignancy survey before the use of ustekinumab for the treatment of psoriasis in patients with a history of long-term cyclosporine therapy. Further investigation of the interactions between cyclosporine and ustekinumab as well as its clinical significance in the induction of SCC of the oral cavity is required.

\section{References}

1. Margolis D, Bilker W, Hennessy S, Vittorio C, Santanna J, Strom BL. The risk of malignancy associated with psoriasis. Arch Dermatol. 2001;137(6):778-783

2. Chiesa Fuxench ZC, Shin DB, Ogdie Beatty A, Gelfand JM. The Risk of Cancer in Patients with Psoriasis: A Population-Based Cohort Study in 
the Health Improvement Network. JAMA Dermatol. 2016;152(3):282290. doi: 10.1001/jamadermatol.2015.4847

3. Moustou AE, Matekovits A, Dessinioti C, Antoniou C, Sfikakis PP, Stratigos AJ. Cutaneous side effects of anti-tumor necrosis factor biologic therapy: a clinical review. J Am Acad Dermatol. 2009;61(3):486-504. doi: 10.1016/j.jaad.2008.10.060

4. Naldi L. Malignancy concerns with psoriasis treatments using phototherapy, methotrexate, cyclosporine, and biologics: facts and controversies. Clin Dermatol. 2010;28(1):88-92. doi: 10.1016/j.clindermatol.2009.03.003

5. Pouplard C, Brenaut E, Horreau C, Barnetche T, Misery L, Richard MA, et al. Risk of cancer in psoriasis: a systematic review and meta-analysis of epidemiological studies. J Eur Acad Dermatol Venereol. 2013; 27(Suppl. 3): 36-46. doi: 10.1111/jdv.12165

6. Farhi D. Ustekinumab for the treatment of psoriasis: review of three multicenter clinical trials. Drugs Today (Brac). 2010;46(4):259-264. doi: 10.1358/dot.2010.46.4.1464839

7. Uhlenhake EE, Feldman SR. Efficacy and safety of ustekinumab and etanercept for the treatment of psoriasis. Expert Opin Biol Ther. 2010;10(7):1105-1112. doi: 10.1517/14712598.2010.487061

8. Unique mechanism of action. Janssen Biotech Inc. 2017. Available from: http://www.stelarahcp.com/plaque-psoriasis/mechanism-ofaction

9. Young L, Czarnecki D. The rapid onset of multiple squamous cell carcinomas in two patients commenced on ustekinumab as treatment of psoriasis. Australas J Dermatol. 2012;53(1):57-60. doi: 10.1111/j.1440-0960.2011.00853.x

10. Igarashi A, Kato T, Kato M, Song M, Nakagawa H. Efficacy and safety of ustekinumab in Japanese patients with moderate-to-severe plaquetype psoriasis: long-term results from a phase $2 / 3$ clinical trial. J Dermatol. 2012;39(3):242- 252. doi: 10.1111/j.1346-8138.2011.01347.x

11. Krueger GG, Langley RG, Leonardi C, Yeilding N, Guzzo C, Wang Y, et al. A human interleukin-12/23 monoclonal antibody for the treatment of psoriasis. N Engl J Med. 2007;356(6):580-592

12. Leonardi CL, Kimball AB, Papp KA, Yeilding N, Guzzo C, Wang Y, et al. Efficacy and safety of ustekinumab, a human interleukin-12/23 monoclonal antibody, in patients with psoriasis: 76-week results from a randomised, doubleblind, placebo-controlled trial (PHOENIX 1). Lancet. 2008;371(9625):1665-16674. doi: 10.1016/S0140-6736(08)607254

13.Papp KA, Langley RG, Lebwohl M, Krueger GG, Szapary P, Yeilding N, et al. Efficacy and safety of ustekinumab, a human interleukin-12/23 monoclonal antibody, in patients with psoriasis: 52-week results from a randomised, doubleblind, placebo-controlled trial (PHOENIX 2). Lancet. 2008;371(9625):1675-1684. doi: 10.1016/S01406736(08)60726-6
14. Tsai TF, Ho JC, Song M, Szapary P, Guzzo C, Shen YK, et al. Efficacy and safety of ustekinumab for the treatment of moderate-to-severe psoriasis: a phase III, randomized, placebo-controlled trial in Taiwanese and Korean patients (PEARL). J Dermatol Sci. 2011;63(3):154-163. doi: 10.1016/j.jdermsci.2011.05.005

15. Gordon KB, Papp KA, Langley RG, Ho V, Kimball AB, Guzzo C, et al. Long-term safety experience of ustekinumab in patients with moderate to severe psoriasis (Part II of II): results from analyses of infections and malignancy from pooled phase II and III clinical trials. J Am Acad Dermatol. 2012;66(5):742-751. doi: 10.1016/j.jaad.2011.06.041

16. Lebwohl M, Leonardi C, Griffiths CE, Prinz JC, Szapary PO, Yeilding N, et al. Long-term safety experience of ustekinumab in patients with moderate-to-severe psoriasis (Part I of II): results from analyses of general safety parameters from pooled Phase 2 and 3 clinical trials. J Am Acad Dermatol. 2012;66(5):731-741. doi: 10.1016/j.jaad.2011.06.011

17. Papp KA, Griffiths CE, Gordon K, Lebwohl M, Szapary PO, Wasfi Y, et al. Long-term safety of ustekinumab in patients with moderate-tosevere psoriasis: final results from 5 years of follow-up. Br J Dermatol. 2013;168(4);844-854. doi: 10.1111/bjd.12214

18. Sorenson E, Koo J. Evidence-based adverse effects of biologic agents in the treatment of moderate-to-severe psoriasis: Providing clarity to an opaque topic. J Dermatolog Treat. 2015;26(6);493-501, doi: 10.3109/09546634.2015.1027167

19. Reich K, Papp KA, Griffiths CE, Szapary PO, Yeilding N, Wasfi Y, et al. An update on the long-term safety experience of ustekinumab: results from the psoriasis clinical development program with up to 4 years of follow-up. J Drugs Dermatol. 2012;11(3):300-312.

20. Papp K, Gottlieb AB, Naldi L, Pariser D, Ho V, Goyal K, et al. Safety Surveillance for Ustekinumab and Other Psoriasis Treatments From the Psoriasis Longitudinal Assessment and Registry (PSOLAR). J Drugs Dermatol. 2015;14(7):706-714.

21. Gottlieb AB, Kalb RE, Langley RG, Krueger GG, de Jong EM, Guenther L, et al. Safety observations in 12,095 patients with psoriasis enrolled in an international registry (PSOLAR): experience with infliximab and other systemic and biologic therapies. J Drugs Dermatol. 2014;13(12):1441-1448.

22.Tsimplaki E, Argyri E, Xesfyngi D, Daskalopoulou D, Stravopodis DJ, Panotopoulou E. Prevalence and expression of human papillomavirus in 53 patients with oral tongue squamous cell carcinoma. Anticancer Res. 2014;34(2):1021-1025.

23. Saghravanian N, Ghazi N, Meshkat Z, Mohtasham N. Human Papillomavirus in Oral Leukoplakia, Verrucous Carcinoma, Squamous Cell Carcinoma, and Normal Mucous Membrane. Oman Med J. 2015;30(6):455460. doi: 10.5001/omj.2015.89 